\title{
Molecular Mechanism of Shoot Determinacy and Flowering in Arabidopsis
}

\author{
Z.R. Sung, L.-J. Chen, and Y.-H. Moon ${ }^{1}$ \\ Department of Plant and Microbial Biology, University of California, Berkeley, CA 94720 \\ N. Yoshida \\ Biotechnology Group, Life Science Laboratory, Mitsui Chemicals, Inc., \\ 1144 Togo, Mobara-shi, Chiba, 297-0017 Japan
}

Flowering is controlled by a number of endogenous and environmental factors (Martinez-Zapater et al., 1994). The environmental factors include day-length, temperature, and stress conditions, while the endogenous factors include age, circadian rhythm, hormone, sugar content, etc.. These factors or signals are perceived and transmitted to the nucleus to cause changes in gene expression that would lead to flower development.

Flower development is usually preceded by changes in shoot development. In Arabidopsis, the vegetative shoot does not undergo internode el*ongation and is called a rosette shoot. Upon floral induction, the shoot bolts and produce an inflorescence on which flowers arise. The Arabidopsis shoot undergoes two major phase changes (Poethig, 1990). The first phase change is the vegetative to reproductive switch. It involves the switch from the rosette to the inflorescence development which results in the lengthening of the stem internode (bolting), shortening of the leaf petiole, and the development of the axillary branches. This phase transition is regulated by a large number of flowering time genes. In Arabidopsis, a facultative long day plant, more than 50 genes have been identified that are involved in the signaling pathway of flowering and flower development (Blasquez 2000). Many of these genes are transcription factors, such as the FLOWERING LOCUS C (FLC, Sheldon et al., 2000), CONSTANS (CO, Putterill et al., 1995); others may be involved in signaling processes, such as FLOWERING LOCUST (FT, Kardialsky et al., 1999), TERMINALFLOWER I (TFLl, Shannon and Meeks-Wagner, 1991; Bradley et al., 1997), etc. If these genes are rendered nonfunctional, the plant will flower later or earlier than wild-type (WT) by producing more or fewer rosette leaves than WT. The second phase change involves the development of the flower rather than the branches on the main inflorescence shoot. Genes such as $L E A F Y$ (LFY, Weigel et al, 1992), APETALA 1 (AP1, Schultz and Haughn, 1991), are important in specifying flower initiation. A large number of genes are involved in specifying flower organ identity. Many of these encode the "MADS" box genes, such as AGAMOUS $(A G)$, API, AP3 and PISTILLATA (PI) (Ng and Yanofsky, 2000; Ng and Yanofsky, 2001a). The flower meristem identity genes were shown to activate $A P 3$ and $P I$. In spite of their role in the second phase transition, $A P I$ and $L F Y$ are implicated in flowering, the first phase transition, as evidenced by early flowering in transgenic plants that express $A P I$ or $L F Y$ ectopically (Mandel and Yanofsky, 1995; Weigel and Nilsson, 1995). Thus there appears to be interaction between the regulation of the two phases. In addition, flower meristem is formed at the time of bolting or stem elongation. Thus, while the three distinct morphological features indicate two phase transitions, it was also proposed that there is only one major transition, the vegetative to flower transition in Arabidopsis (Fig. 1, Hempel and Feldman, 1994).

There are several models of flowering. In general, the models propose the presence of floral repressors or floral activators that, in response to the flowering signals, regulate the flowering pathway (Sheldon et al.,

Received for publication 16 Oct. 2001. Accepted for publication 4 Feb. 2003.We are grateful to Denise Schichnes and Steven Ruzin at the Biological Imaging Facility, College of Natural Resources, Univ. of California, for assistance with microscopy and image processing, and to M.A.Yund for critical reading of the manuscript. Supported by U.S. Dept. of Agriculture, grant number 99-353017984, funds from Norvatis Agricultural Discovery Institute to Z.R.S., and a Korean Government fellowship (KOSEF) to Y.H.M.

${ }^{1}$ Current address: Dept. of Molecular Biology, Pusan National Univ., Busan 609-735, Korea.
2000, Simpson et al., 2001). A more comprehensive model proposes flowering as a part of shoot maturation process (Schultz and Haughn, 1991). Current research aims at clarifying the relationship among the various genes and group them into different, yet overlapping, signaling pathways, and deciphering the molecular mechanism of how the repressors work, e.g., what genes they repress, and how the repression is overcome to allow flowering.

The EMBRYONICFLOWER (EMF) genes are required for vegetative development . Molecular characterization of these two genes (Aubert et al., 2001; Yoshida et al., 2001) have provided information on the mechanism of floral repression during vegetative development.

\section{The EMF genes}

The $E M F$ genes were identified by the isolation of the seedling lethal mutants with very distinct features. The weak mutants produce a small inflorescence upon germination and a few flowers that were sterile (Fig. 2). All leaves are small and petiole-less, thought to be cauline leaves. The strong mutants cannot even produce inflorescence or flower, all lateral organs eventually develop into carpels (Sung et al., 1992; Yang et al., 1995). The mutants have embryonic phenotypes (Bai et al., 1995), indicating that these genes are expressed in the embryo and and implying that the mutants are committed to flowering or reproductive state during embryogenesis. There are 13 mutants isolated to date that belong to two complementation groups, EMF1 and $E M F 2$ (Table 1).

Cloning of the EMF1 gene revealed that it encodes a novel protein with little homology to any genes of known function (Aubert et al., 2001). The predicated amino acid sequence contains certain motifs that include nuclear localization signals, phosphorylation sites, an ATP/GTP binding motif, and a LXXLL motif. The LXXLL motif has been demonstrated to mediate the binding of steroid receptor coactivator complexes to a nuclear receptor (Heery et al., 1997; Torchia et al., 1997). In plants, it has been identified in the RGA and GAI

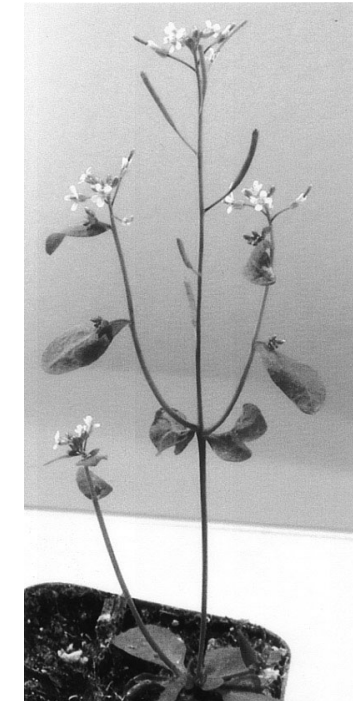

Flower

Flower

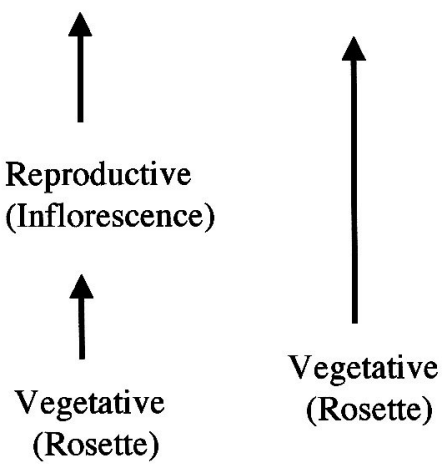

Fig. 1. Possible major phase transitions during Arabidopsis main shoot development. 

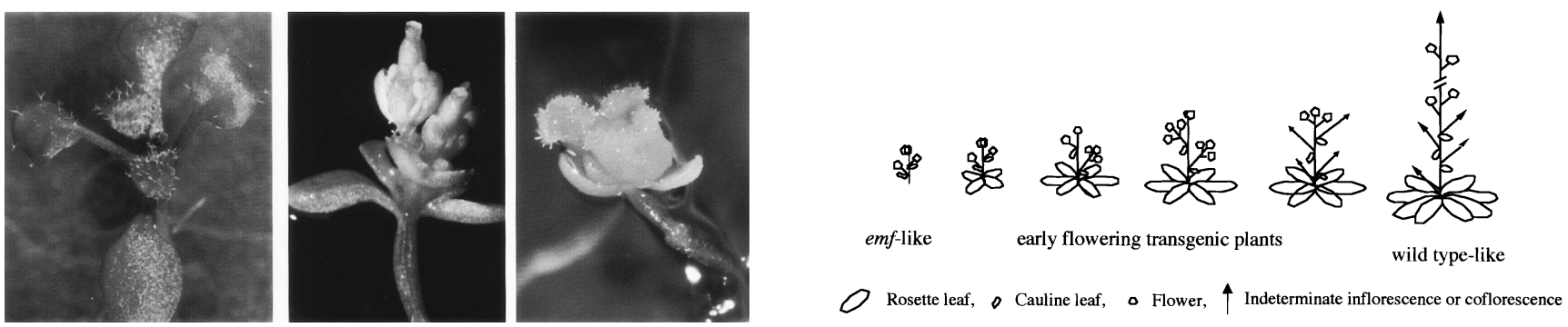

Fig. 2. Phenotypes of $E M F$ mutants. (left) wild-type; (middle) weak phenotype, e.g., emf1-1, emf2-1; (right) strong phenotype, e.g., emf1-2, emf1-3.

Fig. 3. EMF transgenic plants. (left) emf-like transgenic plants, (middle) earlyflowering terminal flower transgenic plants, (right) wild-type-like plant.

Table 1. emf mutant alleles (Goodrich, personal communication).

\begin{tabular}{llccccc}
\hline Gene & Allele & Phenotype & $\begin{array}{c}\text { Original } \\
\text { designation }\end{array}$ & Mutagen & Source & $\begin{array}{c}\text { Genetic } \\
\text { background }\end{array}$ \\
\hline EMF1 & emf1-1 & weak & 501 & EMS & Sung lab, UC Berkeley & Col \\
& emf1-2 & strong & G3-152 & $\gamma$ - ray & same as above & Col \\
& emf1-3 & strong & 4902 & Ac/Ds & C. Dean, John Innes Institute & Ler \\
& emf1-4 & strong & --- & T-DNA & P. Springer, UC Riverside & Ler \\
EMF2 & emf2-1 & weak & 298 & EMS & Sung lab, UC Berkeley & Col \\
& emf2-2 & weak & G29-49 & $\gamma$ - ray & same as above & Col \\
& emf2-3 & weak & G14-138 & $\gamma$ - ray & same & Col \\
& emf2-4 & weak & D513 & DEB & Same & Ler \\
& $e m f 2-5$ & weak & SP1 & EMS & S. Poethig, U. of Penn. & Ler \\
& $e m f 2-6$ & weak & SP2 & DEB & S. Poethig, U. of Penn. & Ler \\
& $e m f 2-7$ & weak & DEB & & K. Barton, U. of Wisconsin & Col, g11 \\
& $e m f 2-8$ & weak & cyr & EMS & J. Deikman, Penn State U. & Col \\
\hline
\end{tabular}

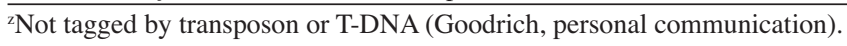

proteins, both putative transcriptional regulators in the gibberellic acid signal transduction pathway (Peng et al., 1997; Silverstone et al., 1998). These two proteins and EMFI also display homopolymeric stretches of serine residues. In addition, a region of the EMF1 protein between amino acids 901 and 1034 displays similarity (identities: 23\%, positives: $37 \%$ ) with two members of a nuclear receptor gene family. This gene family comprises one of the most abundant groups of transcriptional regulators in mammals with members involved in various developmental processes (Sluder et al., 1999). The identification of these motifs indicates that $E M F 1$ could function as a transcriptional regulator during shoot development.

$E M F 2$ encodes a $71.7 \mathrm{kDa}$ protein with sequence homology to two known Arabidopsis proteins, FERTILIZATION INDEPENDENT SEED (FIS) and VERNALIZATION (VRN)2, in the region containing $\mathrm{C}_{2} \mathrm{H}_{2}$ and an acidic W/M domain (Yoshida et al., 2001). These proteins also share homology with a newly identified Polycomb Group (Pc-G) protein $\mathrm{Su}(\mathrm{z}) 12$ of Drosophila. Mutations of the $\mathrm{Su}(z) 12$ gene cause typical phenotypes of Pc-G mutants such as homeotic transformations and misexpression of homeobox genes in the developmental process of Drosophila. Currently, three classes of Pc-G gene homologs are reported in Arabidopsis. These are CURLY LEAF (CLF) (Goodrich et al., 1997), FISI/MEDEA (MEA) (Luo et al., 1999), and FIS3/FERTILIZATIONINDEPENDENT ENDOSPERM (FIE) (Ohad et al., 1999). Thus, $E M F 2, V R N 2$, and FIS2 are the fourth class of Pc-G gene homologs in Arabidopsis. In animals, Pc-G proteins form large protein complexes (Tie et al., 1998, Tie et al., 2001; Shao et al., 1999) and act to remodel chromatin structures altering the accessibility of DNA to factors required for transcription. In plants, protein-protein interactions were examined among the $F I S$ genes and only $M E A-F I E$ interaction was detected by the yeast two-hybrid system (Luo et al., 2000; Yadegari et al., 2000). The role of the Arabidopsis Pc-G homologs in chromatin-remodeling remains to be investigated, protein interaction between $C L F$ and $E M F 2$ is an intriguing proposition.

The expression pattern of the EMF1 and EMF2 RNA is highly similar; both RNAs are found in most plant organs and at all ages of the plant. Since the mutant phenotypes are very similar, these genes display functional similarity. The predicted protein sequences suggest that they are both likely to be nuclear proteins. Together with the genetic interaction studies (Chen et al., 1997), these findings indicate that the two proteins may interact to regulate gene expression. We compared global gene expression pattern of emf mutants with that of WT. While there are many genes that show differential expression patterns between the mutants and WT, the most notable finding is that many flower-specific homeotic genes are highly expressed in the mutants shortly after gemination (data not shown). This is consistent with our earlier results showing ectopic $A P I$ and $A G$ expression in emf mutants (Chen et al., 1997). Since mutant seedlings are morphologically similar to WT, our results suggest that the loss-of-function emf mutations enabled flowerspecific homeotic gene expression in the seedlings. The $C L F$ gene is also known to suppress $A G$ expression, and when mutated, causes ectopic $A G$ expression, early flowering and curly leaves.

\section{EMF transgenic plants}

Transgenic plants harboring CaMV 35S promoter::EMF1 or $E M F 2$ in sense and antisense directions have been analyzed. Again, EMFI and $E M F 2$ transgenic plants have similar phenotypes. The antisense plants displayed a spectrum of emfl-like, early-flowering and WT-like phenotypes (Fig. 3). The emfl-like plants were sterile, but the earlyflowering plants were fertile and could grow in soil. The emfl-like transgenic plants, like emfl mutants, lacked rosette leaves and flowered at 14-16 d after sowing. Early-flowering transgenic plants produced 2-8 rosette leaves and flowered at $16-20 \mathrm{~d}$ after sowing. In the same growth conditions WT-like plans produced 10-13 rosette leaves and flowered at $\approx 25 \mathrm{~d}$ after sowing. The endogenous $E M F 1$ transcript levels of the early-flowering and EMFl-like antisense plants were greatly decreased relative to WT-like antisense plants and WT plants. The fact that fertile early-flowering plants with normal leaves and flowers were found in plants with reduced EMF activities indicate that $E M F$ genes are indeed involved in regulating flowering time.

\section{Possible mechanism of floral repression}

All the emfl-like and early-flowering transgenic plants made the shift from an indeterminate to determinate growth habit by producing terminal flowers (Fig. 2). Additionally, some early-flowering plants showed a sympodial branching phenotype during shoot development, a phenotype seen in nature (Foster and Gifford, Jr., 1974) but never observed in WT Arabidopsis. The activation of MADS box genes in the emf mutant seedlings suggests that EMF1 and EMF2 are involved in the 
repression of MADS box gene expression. Ectopic expression of some MADS box genes causes early flowering and produces terminal flowers as in $35 S:: A P 1,35 S:: A G$ transgenic plants (Mandel and Yanofsky, 1995; Weigel and Nilsson, 1995), consistent with the notion that the flower homeotic genes act downstream from $E M F$. Because $E M F 2$ encodes a PcG-like protein, thus it may function like the Drosophila PcG protein by maintaining the repression of homeotic genes via chromatin remodeling. To explain flowering in mature Arabidopsis plants or plants grown under long day conditions, we propose that the floral activators such as $L F Y, A P I$, etc. may gain access to the flower homeotic genes, and overcome the floral repression. The diverse phenotypes seen among the $E M F$ transgenic plants suggest that $E M F$ proteins may interact with different proteins and form different complexes during development, thus explaining the pleiotropic effects of $E M F$ on multiple phases of shoot development.

In summary, we found that 1) suppression of $E M F$ activities shortens the vegetative phase in transgenic plants, 2) alteration of $E M F$ activities causes shoot determinacy and affects inflorescence architecture, 3) EMF1 encodes a putative transcription regulator, $E M F 2$ a potential Pc-G protein, and 4) The two proteins may modulate chromatin structure and repress flower homeotic gene expression. The diverse phenotypes seen among the $E M F$ transgenic plants suggest that $E M F$ proteins may interact with different proteins and form different complexes during development.

\section{Literature Cited}

Aubert, D., L. Chen, Y.H. Moon, D. Martin, L.A. Castle, C.H. Yang, and Z.R. Sung. 2001. EMF1, a novel protein involved in the control of shoot architecture and flowering in Arabidopsis. Plant Cell. 13:1865-1875.

Bai, S. and Z.R. Sung. (1995), The role of EMF1 in regulating the vegetative and reproductive transition in Arabidopsis thaliana (Brassicaceae). Amer. J. Bot. 82 (9): 1095-1103.

Bradley, D., O. Ratcliffe, C. Vincent, R. Carpenter, and E. Coen. 1997. Inflorescence commitment and architecture in Arabidopsis. Science 275, 80-83.

Blázquez, M. 2000. Flower development pathways. J. Cell Sci. 113:35473548 .

Chen, L., J.C. Cheng, L. Castle, and Z.R. Sung. 1997. EMF genes regulate Arabidopsis inflorescence development. Plant Cell. 9:2011-24.

Foster, A.S. and E.M. Gifford, Jr. 1974. Comparative morphology of vascular plants. W.H. Freeman and Co., San Francisco.

Goodrich, J., P. Puangsomlee, M. Martin, D. Long, and E.M. Meyerowitz. 1997. APolycomb-group gene regulates homeotic gene expression in Arabidopsis. Nature 386:44-51.

Heery, D.M., E. Kalkhoven, S. Hoare, and M.G. Parker. 1997. A signature motif in transcripional co-activators mediates binding to nuclear receptors. Nature 387:733-736.

Hempel, F.D. and L.J. Feldman. (1994), Bidirectional inflorescence development in Arabidopsis thaliana: acropetal initiation of flowers and basipetal initiation of paraclades. Planta. 192(2):276-286.

Kardailsky, I., V.K. Shukla, J.H. Ahn, N. Dagenais, S.K. Christensen, J.T. Nguyen, J. Chory, M.J. Harrison, and D. Weigel. 1999. Activation tagging of the floral inducer FT. Science 286:1962-1965.

Luo, M., P. Bilodeau, A. Koltunow, E.S. Dennis, W.J. Peacock, and A.M. Chaudhury. 1999. Genes controlling fertilization-independent seed development in Arabidopsis thaliana. Proc. Natl. Acad. Sci. 96:296-301.

Luo, M., P. Bilodeau, E.S. Dennis, W.J. Peacock, and A. Chaudhury. 2000 Expression and parent-of-origin effects for FIS2, MEA, and FIE in the endosperm and embryo of developing Arabidopsis seeds. Proc. Natl. Acad. Sci. 97:10637-10642.

Mandel M. and M.F. Yanofsky. 1995. A gene triggering flower formation in Arabidopsis. Nature 377:522-524.

Martínez-Zapater, J.M., G. Coupland, C. Dean, and M. Koornneef. 1994. The transition to flowering in Arabidopsis, p. 403-433. In: E.M. Meyerowitz and C.R. Somerville (eds.). Arabidopsis. Cold Spring Harbor Lab. Press., Cold Spring Harbor, N.Y.

Ng, M. and M.F. Yanofsky. 2000. Three ways to learn the ABCs. Current Opinion in Plant Biol. 3(1):47-52.
Ng, M. and M.F. Yanofsky. 2001. Function and evolution of the plant MADSbox gene family. Nat. Rev. Genet. Mar. 2(3):186-95.

Ng, M. and M.F. Yanofsky. 2001. Activation of the Arabidopsis B Class Homeotic Genes by APETALA1. Plant Cell. 13:739-754.

Ohad, N., R. Yadegari, L. Margossian, M. Hannon, D. Michael, J.J Harada, R.B. Goldberg, and R.L. Fischer. 1999. Mutation in FIE, a WD polycomb gene, allow endosperm development without fertilization. Plant Cell. 11: 407-415.

Peng, J., P. Carol, D.E. Richards, K.E. King, R.J. Cowling, G.P. Murphy, and N.P Harberd. 1997. The Arabidopsis GAI gene defines a signaling pathway that negatively regulates gibberellin responses. Genes Dev. 11:3194-3205.

Poethig, R.S. 1990. Phase change and the regulation of shoot morphogenesis in plants. Science 250:923-930.

Putterill, J.,F. Robson, K. Lee, R. Simon, and G. Coupland. 1995. The CONSTANS gene of Arabidopsis promotes flowering and encodes a protein showing similarities to zinc finger transcription factors. Cell. 80:847-857.

Sablowski, R.W and E.M. Meyerowitz. 1998. A homolog of NO APICAL MERISTEM is an immediate target of the floral homeotic genes APETALA3/ PISTILLATA [published erratum appears in Cell 92(4):following 585. 20 Feb. 1998.]. Cell. 9:92:93-103.

Schultz, E.A. and G.W. Haughn. 1991. LEAFY, a homeotic gene that regulates inflorescence development in Arabidopsis. Plant Cell. 3:771-781.

Schultz, E.A. and G.W. Haughn. 1993. Genetic analysis of the floral initiation process (FLIP) in Arabidopsis. Development 119:745-765.

Shannon, S. and D.R. Meeks-Wagner. 1991. Genetic interactions that regulate inflorescence development in Arabidopsis. Plant Cell. 3:877-892.

Shao, Z., F. Raible, R. Mollaaghababa, J.R. Guyon, C.T. Wu, W. Bender, and R.E. Kingston. 1999. Stabilization of chromatin structure by PRC1, a Polycomb complex. Cell. 98:37-46.

Sheldon, C.C., D.T. Rouse, E.J. Finnegan, W.J. Peacock, and E.S. Dennis. 2000 The molecular basis of vernalization: The central role of FLOWERING LOCUS C (FLC). Proc. Natl. Acad. Sci. 28:97(7):3753-8.

Silverstone, A.L., C.N. Ciampaglio, and T.-p. Sun. (1998) The Arabidopsis RGA gene encodes a transcriptional regulator repressing the gibberellin signal transduction pathway. Plant Cell. 10:155-169.

Simpson G. T. Gendall, and C. Dean. 2001. EMBO workshop on the molecular basis of the floral transition. John Innes Centre, Norwich, U.K. 10-14 July.

Sluder, A.E., Mathews, S.W., D. Hough, V.P. Yin, C.V. Maina. 1999. The nuclear receptor superfamily has undergone extensive proliferation and diversification in nematodes. Genome Res. 9(2):103-120.

Sung, Z.R., A. Belachew, B. Shunong, and R. Bertrand-Garcia. 1992. EMF, an Arabidopsis gene required for vegetative shoot development. Science 258: $1645-1647$.

Tie, F., T. Furuyama, and J.P. Harte. 1998. The Drosophila Polycomb Group proteins ESC and $\mathrm{E}(\mathrm{Z})$ bind directly to each other and co-localize at multiple chromosomal sites. Development 125:3483-3496.

Tie, F., T. Furuyama, J. Prasad-Sinha, E. Jane, and P.J. Harte. 2001. The Drosophila Polycomb Group proteins ESC and E(Z) are present in a complex containing the histone-binding protein $\mathrm{p} 55$ and the histone deacetylase RPD3. Development 128:275-286.

Torchia, J., D.W. Rose, J. Inostroza, Y. Kamei, S. Westin, C.K. Glass, and M.G. Rosenfeld. 1997. The transcriptional co-activator p/CIP binds CBP and mediates nuclear-receptor function. Nature 387:677-684.

Weigel, D., J. Alvarez, D.R. Smyth, M.F. Yanofsky, and E.M. Meyerowitz. 1992. LEAFY controls floral meristem identity in Arabidopsis. Cell. 69 843-859.

Weigel, D. and O. Nilsson. 1995. A developmental switch sufficient for flower initiation in diverse plants. Nature 377:495-500.

Yadegari, R.T. Kinoshita, O. Lotan, G. Cohen, A. Katz, Y. Choi, A. Katz, K. Nakashima, J.J. Harada, R.B. Goldberg, R.L. Fischer, and N. Ohad. 2000 Mutations in the FIE and MEA genes that encode interacting polycomb proteins cause parent-of-origin effects on seed development by distinct mechanisms. Plant Cell. 12:2367-2382.

Yang, C.H., L.J. Chen, and Z.R. Sung. 1995. Genetic regulation of shoot development in Arabidopsis: role of the EMF genes. Dev. Biol. 169: 421-435.

Yoshida, Y., Y. Yanai, L. Chen, Y. Kato, J. Hiratsuka, T. Miwa, Z.R. Sung, and S. Takahashi. 2001. EMBRYONIC FLOWER2, a novel polycomb group protein homolog, mediates shoot development in Arabidopsis. Plant Cell. 13:2471-2481. 